Contact the AATS Development Office: 978-252-2200, Ext. 544

\section{Apply for AATS Graham Foundation Programs}

The AATS Graham Foundation recently started accepting applications for several programs. You can now apply for:

\section{Every Heartbeat Matters Travel Award \\ Deadline: January 15}

Available to surgeons from around the world working within under-resourced medical centers, the Every Heartbeat Matters Travel Award looks to aid deserving applicants with the cost of travel to attend the AATS Annual Meeting, which is to take place this year in San Diego, California.

Learn from the Masters

Deadline: January 15
Providing a unique educational experience, the Learn from the Masters program pairs awardees who have recently completed their residency or fellowship with leading cardiac surgeons. During their three- to six-month stay the awardee will work within a full clinical position, which includes full clinical service access.

\section{Graham Surgical Investigator}

Deadline: January 15

Supporting innovating clinical or transitional research within the field of cardiothoracic surgery, the Graham Surgical Investigator awards a limited number of proposals to topics of research varying from robotically assisted surgery, minimally invasive surgery, to other applications of new and innovative technologies within cardiothoracic surgery.

For more information on these programs or others that will be accepting applications soon, visit: www.AATSGrahamFoundation.org

\section{The Western Thoracic Surgical Association}

\section{WTSA 44th Annual Meeting Call for Abstracts}

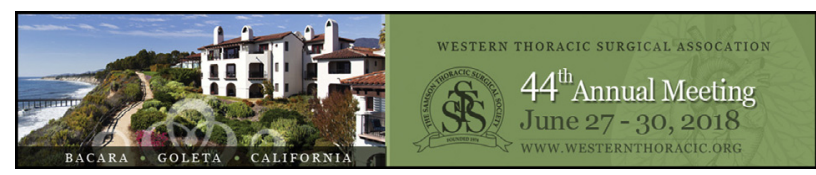

The WTSA's 44th Annual Meeting will be held at the Bacara in Goleta, California, from June 27 to 30, 2018. Abstract submissions are now being accepted for presentation consideration at the 2018 WTSA Annual Meeting through Monday, January 8, 2018, at 11:59 PM Pacific Standard Time. Visit the WTSA Web site at westernthoracic.org to view author instructions and to submit abstracts.

\section{WTSA Traveling Fellowship for Residents, Trainees, and Practicing Surgeons}

The goal of this traveling fellowship is to promote interaction and learning between residents/trainees/practicing surgeons and WTSA members. The traveling fellow will visit a University-affiliated or academic practice of his/her choosing, within the boundaries of the WTSA (Alaska, Arizona, California, Colorado, Hawaii, Idaho, Montana, Nevada, New Mexico, Oregon, Utah, Washington, Wyoming along with Canadian provinces of Alberta, British Columbia, Manitoba, and Saskatchewan), for a period of one to two weeks, under the sponsorship of a Western member at the hosting institution. The traveling fellow does not need to be a WTSA member; the award is open to any resident/ trainee/practicing surgeon. Reimbursement of up to $\$ 5,000$ will be provided to the traveling fellow, to defray reasonable costs for travel, lodging and meals.

To be eligible for consideration, the following materials should be submitted to the Association Office via the online application at westernthoracic.org no later than December 15, 2017:

Online Application to include the following uploads:

- Applicant responses to survey questions

- Curriculum Vitae or Resume

- Letter of support from the Chief of Surgery at applicant's primary hospital

- Letter of support from a current Active or Senior WTSA member

The award will be announced publicly at the 44th WTSA Annual Meeting, June 27-30, 2018, in Goleta, California; it is requested that the awardee be present at this meeting to receive the award. The awardee will contact the sponsoring member and make arrangements to complete the fellowship during the period of July 1, 2018, to June 25, 2019. It is requested that the awardee attend the 45th WTSA Annual Meeting, June 26-29, 2019, in Olympic Valley, California, and make an oral presentation at that meeting about the traveling fellowship experience.

Visit the WTSA Web site at westernthoracic.org to view complete Traveling Fellowship details and to submit your application. 